ISSN 1936-5098

CAE Working Paper \#09-09

A Marketing Scheme for Making Money off Innocent People:

A User's Manual

by

Kaushik Basu

May 2009 
June 10, 2009

\title{
A Marketing Scheme for Making Money off Innocent People: A User's Manual
}

\section{Kaushik Basu}

Department of Economics

Cornell University

Ithaca, New York 14853

Email:kb40@cornell.edu

\begin{abstract}
Firms often give away free goods with the product that they sell. Firms often give stock options to their top management and other employees. Mixing these two practices-giving stock options to consumers who buy the firm's product-, creates a deadly brew. Large numbers of consumers can be lured into buying this product, giving the entrepreneur huge profits and the consumers a growing profit share. But this is a camouflaged Ponzi that will ultimately crash. By analogy it is argued that the common practice of giving stock options to employees can be a factor behind financial crashes.
\end{abstract}

Key words: marketing, stock options, financial scams, product bundling

JEL Classification numbers: M30, G18, G32, L20, D92

Acknowledgements I am grateful to Levon Barsheghyan, Dan Benjamin, Brian Dillon, Nick Kiefer, Annemie Maertens, Asani Sarkar, Karl Shell, Ariel Rubinstein, and Jorgen Weibull for comments and suggestions. 


\section{A Marketing Scheme for Making Money off Innocent People: A User's Manual}

\section{The Idea}

This paper outlines a new marketing strategy that can generate large profits by selling a product that may be of questionable value to the consumer. All one needs is a little ingenuity, and a lack of moral qualms. Both these qualities, especially the latter, are available in ample supply in today's world. The scheme in question, while novel, belongs to a large class of related scams that have been used in the past. What is interesting is that this scheme works even when consumers are fully rational. The particular marketing strategy suggested here does not technically violate the law, even though it does lie barely beyond the boundary of what is unquestionably legal. Borrowing a term from the Economist magazine, it is best to describe this marketing strategy as 'alegal'. The law will no doubt catch up on it with a lag, as it does on most scams. In the mean time, here is the user's manual.

The scheme combines two widely used marketing strategies (both of which are legal in most nations) but in combining them creates a deadly brew. First, it is a standard ploy in marketing to give away something for free (or what guileless consumers take to be free) with the product that is being sold. We often get free music systems with the new car, free CDs with the new music system, and a free ounce of toothpaste with the $3.8 \mathrm{oz}$ tube. Of course, it is not evident what "free" means in these cases. Recently, when I bought a Sudoku book, I was touched to find that, in addition to the 298 Sudokus in the book, the publisher had given two "bonus Sudokus", without charging for them.

Second, we are all familiar with modern corporations and firms doling out handsome amounts of stock options to their top management and, increasingly, even to rank-and-file employees. Basically this amounts to giving employees the right to buy the company's stocks at a low price, thereby creating employee interest in increasing the price of shares.

The marketing scheme being suggested here is to give away 'free goods' with the main product being sold; and to make those free goods stock options. In other words, what is being proposed is the idea of giving stock options to those buying the product being sold by the firm. It 
is like Honda handing out Honda shares to each person who buys a Honda car. If the price of the good is appropriately set and the amount of shares given out with each product is worked out in a particular way (explained below), this can create a huge demand for the product and can cause profits to rise steadily, giving the entrepreneur who starts this scheme a large amount of profit. Essentially, this brew of two standard practices, mixed in carefully-calculated proportions, creates a strange chemistry which is best thought of as a camouflaged Ponzi. I shall refer to this, in brief, as a 'Camoponzi'.

Here is how the scheme works. Suppose you are an entrepreneur starting to manufacture some product - cars, trucks, refrigerators. It can be anything. Let me call it by the neutral name of 'hotash'. With each unit of hotash the consumer who buys it will be a given some shares of your company for free. If the proportions are worked out right - and I am about to show you how it can be done - then it is possible to flood the market with hotashes. Consumers will find it worthwhile to buy huge amounts of hotashes and you as the entrepreneur will earn large profits. Like all such financial scams, it works as long as everybody believes that it will work.

\section{The Arithmetic}

Here is the user's manual. I will later show why there will be demand for it from the consumers and how it can turn in huge profits. Let us suppose the cost of producing each unit of hotash is $c$. Since this can be a pretty worthless good, $c$ will be low. I shall simply assume $c \geq 0$. You, the entrepreneur, should fix the price of hotash (for all times to come) at $p(>c)$. Hence, every time a unit of hotash is sold, it generates a profit of $p-c \equiv \pi$.

Time is broken up into periods, for instance, months. In period 1, the entrepreneur should offer for sale 1 unit of hotash and, along with it, a half-share of the company's profit. The remainder of the share remains with the entrepreneur. Hence, in period 1, the entrepreneur earns $\pi / 2$ and the consumer gets one hotash and earns $\pi / 2$.

In period 2, let the entrepreneur manufacture and sell 2 hotashes. Each hotash is offered with a share of $1 / 8=1 / 2^{3}$ of the company's profit. So from period 2 onwards, $1 / 2$ profit goes to the buyer of period $1,1 / 2^{3}$ share of profit goes to each of the two buyers in period 2 and the entrepreneur gets $1-\frac{1}{2}-\frac{2}{2^{3}}=\frac{1}{4}$. 
Now, let me take the inductive leap and specify behavior in period $m$, for each period $\mathrm{m}=$ $1,2,3, \ldots$, endlessly. The number of hotashes manufactured and sold should be $2^{m-1}$. With each hotash, give away a profit share of $\frac{1}{2^{2 m-1}}$. Note that for $\mathrm{m}=1$ and $\mathrm{m}=2$, this is exactly what was described above.

Let me now show why everybody-the consumers and the entrepreneur-gains from these offerings. Let us first consider the entrepreneur. By the time period $m$ comes, she has given away the following shares in periods $1,2, \ldots, m$ :

$$
\frac{1}{2}, 2 \times \frac{1}{2^{3}}, \ldots, 2^{m-1} \times \frac{1}{2^{2 m-1}} .
$$

Adding these up we find that she has given up a total share of $\frac{1}{2}+\frac{1}{4}+\ldots+\frac{1}{2^{m}}$, which is, as is easily checked, equal to $1-\frac{1}{2^{m}}$. Hence, in period $m$, she gets to keep $\frac{1}{2^{m}}$ share of the profit. In period $m$, total profit is $2^{m-1} \pi$. Therefore, the profit earned by the entrepreneur is $\pi / 2$. Since $m$ has vanished from the expression, it follows that the entrepreneur earns a profit of $\pi / 2$ in every period. Since $\pi / 2>0$, this is clearly a scheme for endless profiteering.

What we have to show next is that it is worthwhile for the consumers to buy the hotashes that are supplied by the entrepreneur.

Assume all hotashes get sold. Then the total profit in period 1 is $\pi$, in period 2 is $2 \pi$ and in period $m$ is $2^{m-1} \pi$. Hence, the consumer who buys the product in period 1 earns profits in periods $1,2,3,4, \ldots$, as follows:

$$
\frac{\pi}{2}, \pi, 2 \pi, 4 \pi, \ldots
$$

Since $\pi>0$ and this is an exponentially growing series, it makes sense for him to buy the hotash even if the hotash has no intrinsic value to him.

Now consider the cohort of consumers that buys the good in period $m$. The profit earned by such a consumer in periods $m, m+1, \ldots$ is as follows:

$$
2^{m-1} \pi \times \frac{1}{2^{2 m-1}}, 2^{m} \pi \times \frac{1}{2^{2 m+1}}, \ldots
$$

or, $\quad \frac{\pi}{2^{m}}, \frac{\pi}{2^{m-1}}, \ldots$ 
This again is a series that begins with a positive number and then gets doubled each period and so is unbounded from above. It is reasonable to pay a price, namely $p$, in any period $m$ and acquire a hotash along with the share options that are on offer in that period.

Formally, what has just been described is equilibrium behavior in an infinite-horizon game. If other consumers are expected to buy the product, then it is indeed worthwhile for each consumer to buy the product ${ }^{1}$. However, it is also true that, if no one else is expected to buy the product in the future, then it is not worthwhile for a consumer in a particular period to buy the product. In other words, there exists another equilibrium in which the scheme fails. This must not be taken to detract from the fact that the equilibrium in which the scheme succeeds is robust in the sense of being a strict equilibrium, that is, one in which a consumer who deviates unilaterally and does not buy the product actually does worse.

It should be clarified that, while the outcome described above is an equilibrium in the sense of being associated with subgame perfect behavior, no claims are being made of this being a market equilibrium. Indeed, describing a market equilibrium with Ponzis is problematic. It is easy to think of another firm undercutting the one described above by giving consumers a better deal and making more profit. This is because one can make the rise in profit over time steeper. The problem arises from the fact that there is no theory to guide us on how much one can do this without causing a breakdown in consumer confidence. Fortunately, describing a market equilibrium is not the objective of the paper; the objective is to show that a firm can sell a dud product at a positive price and make a profit, by developing a marketing strategy which is a camouflaged Ponzi.

I have glossed over a little on the detail of the individual consumer's decision making. Basically, for a consumer facing a choice of whether or not to buy a hotash, along with the free shares, on offer is a problem of choosing between infinite streams of returns. Buying a hotash generates an infinite stream of returns that comes from the share that one gets, plus the pleasure of driving or playing with or whatever one is supposed to do with a hotash. Let us suppose that this generates the infinite utility stream $x_{1}, x_{2}, x_{3}, \ldots$. If she decides not to buy a hotash, she gets the infinite stream $-p, 0,0, \ldots$. Declaring one of these streams as better than the other is the standard problem of choosing between infinite streams. If we are to make this comparison

\footnotetext{
${ }^{1}$ Even in macroeconomic models of bubbles, which are constructed very differently, we can see this bootstrapping property. The piece of an asset is high today because it is expected to be high tomorrow and this generates a behavior which makes the expectations rational (see Shell, Sidrauski and Stiglitz, 1969).
} 
without any discounting, we tend to run into some tricky problems (Basu and Mitra, 2003). However, one way around this is to be prepared to deal with incomplete preference orderings. A reasonable one is to use the standard idea of utilitarianism (see, for instance, Maskin, 1978) and extend it, incompletely, to infinite streams. This was done in Basu and Mitra (2007). According to this 'utilitarian criterion' an infinite stream, $x \equiv\left(x_{1}, x_{2}, \ldots\right)$ is preferred to $y \equiv\left(y_{1}, y_{2}, \ldots\right)$ if there exists an integer $t$ such that $x_{1}+x_{2} \ldots+x_{t}>y_{1}+y_{2} \ldots+y_{t}$, and, for all $k>t, x_{k}>y_{k}$.

It is now easy to see that, using the utilitarian criterion, it is worthwhile for consumers to buy hotashes, along with the share offerings, no matter how little the value of the hotash itself.

We get the same result if we use the more familiar overtaking criterion, which has been known from the time of Frank Ramsey, analyzed and axiomatized (Brock, 1970), and used in infinite-horizon game theory (Rubinstein, 1979). The reason the above argument remains intact with the overtaking criterion is that, as shown in Basu and Mitra (2007), if a stream $x$ is preferred to a stream $y$, according to the utilitarian criterion, then $x$ is preferred to $y$ under the overtaking criterion (even though the reverse implication does not follow).

Finally, what happens if we want to use the familiar method of discounted present value? If the discount factor is $\delta \in(0,1)$, the present value of stream (3) is given by:

$$
\frac{\pi}{2^{m}(1-2 \delta)}
$$

For $\delta$ close to 1 this will be a large number. Moreover, since hotash can be of zero intrinsic worth its cost of production can be very low. If $c$ is close to zero then $\pi$ is close to $p$. It is immediately clear that while the scheme described above is a specific one, for every $\delta<1$, we can redesign a scheme to make the profit growth sufficiently exponential for hotash to be a good buy for all consumers. Hence, the scheme described here is one in which, if all consumers decide to buy the product whenever it is offered, then all consumers will find it worthwhile to buy and you the entrepreneur will make a large profit.

\section{The Variants}

The scheme that I have described has many variants. For the most part these will be pretty obvious and anybody planning to use this should be able to work out minor variants of it, maybe with the help of his in-house economist or finance specialist. Just to give a flavor of what 
is possible, suppose that you want to avoid the rapid growth in the number of hotashes sold in each period. This is easily done. Pretend that all the hotashes that you have at the start of the project and into the endless future are numbered, 1, 2, 3 and so on. Let us suppose you have decided to manufacture and sell $\mathrm{l}$ hotashes in each period. Then here is what you can do. Sell hotash number 1 exactly with the package of shares that you would do in the above scheme. That is the person buying it gets $1 / 2$ the share of all profits. Those who buy the hotashes numbered 2 and 3, namely the next 2 hotashes, get the shares as specified above, namely, $1 / 8^{\text {th }}$ of all profits. Those who buy the next 4 hotashes, that is, hotashes numbered 4, 5, 6 and 7, will get a profit share of $1 / 32$ of all profits, as above (check for $m=3$ ). And so on.

This will cause a slight change in the calculation of returns since, within a period, there will be different people who would have got hotashes with different amounts of shares. But the essential argument remains the same. For you the entrepreneur the calculation is virtually the same. If consumers use the utilitarian criterion described above, it is easy to see that it is worthwhile for them to buy the product, since the returns stream will eventually outdo the price of the hotash. If consumers are maximizers of discounted present value, then we do have a problem in that the discount factor has to, for later consumers, go endlessly close to 1 . But of course this is just one variant of the above scheme. There are other variants where this problem is avoided.

One can also design other kinds of share options give away, so as to enable the entrepreneur to collect even higher profits. One method is to put into action what may be called a "fading share." This is a share that erodes over time. In other words, it gives a profit share of $s_{1}$ in the first period that the consumer gets the share, a share of $s_{2}$ in the next period, a share of $s_{3}$ in the third period after buying the product and so on, where $s_{1} \geq s_{2} \geq s_{3} \geq \ldots$. By modifying these fading shares in different ways an entrepreneur endowed with some enterprise and ample greed can do a lot for himself. What all these variants share is the feature of being Camoponzis.

\section{The Ethics}

The value of this paper is, hopefully, not what it can do for an enterprising entrepreneur but because it shows up the world for what it is. There are people who have accumulated great wealth by making genuinely worthwhile contributions to society, but there are many who have 
accumulated wealth by developing innovative pricing and marketing schemes, some of which are camouflaged Ponzis. They often contribute to taking our economy into unusual highs and then precipitate a collapse, as we have seen in the recent global financial crisis (Akerlof and Shiller, 2009; Basu, 2009). ${ }^{2}$

This same ethical point is made powerfully in Rubinstein and Spiegler (2008). The motivation in their paper is similar to the one in this paper. They construct a model in which a businessman can sell a dud by “creating a harmful sequence of bilateral transactions" (p. 237), which the buyer accepts. Hence, they show how, contrary to popular perception, the entrepreneur who sells a product widely does not have to be creating value. Despite this common normative concern, the analytical structure of their model is, however, very different from the one in this paper for their model assumes that consumers are less than fully rational.

The scheme I have outlined above shows some of the ways in which common business practices can generate profits for entrepreneurs without creating any value. At times, even the practitioners do not fully understand what they are doing.--Shiller (2000) has written about "naturally occurring Ponzis". It is today common to give out share options to employees and often also to the consultants and lawyers who advise the company. One reason why some of these people agree to work for the firm as employees or as outside consultants is the lure of the future profits. What is implicitly happening in these cases is not totally different from what has been described above. A bubble is being created with the help of a Camoponzi that could eventually blow up.

Without going into full details, here is how it would work. Suppose an entrepreneur has a project which has very low productivity. It could be a consulting firm in which people work hard but what they produce is of little true worth. Suppose each person who works full time in this firm produces output equal to value $\beta$. Suppose each person's labor $\operatorname{costs} c$, where $c / 2<\beta<c$. Clearly the firm does not produce net value. Yet, it can run and earn profits, if the entrepreneur is willing to give stock options in cleverly worked out proportions to the employees. Suppose he sets the salary of each employee at c/2. If people take up this job offer, then, with each employed person the firm will earn a profit of $\beta-c / 2>0$. As the firm grows by employing more and more

\footnotetext{
${ }^{2}$ The market for hotash also helps us get an unusual insight into the positive economics of financial crisis. The close connection between liquidity and crisis has been noted and written about, with the view being often taken that a crisis cannot occur with fully rational agents (for an analytical survey in the context of the current crisis, see Allen and Carletti, 2008). In the market for hotash an illusion of wealth and liquidity is created among consumers, which ultimately leads to a crash. Interestingly, this happens with fully rational agents.
} 
workers, it can earn more and more profits. The only catch is: why will anybody work for this salary? This is where stock options come in. Suppose the firm employs 1 person in period 1 and gives her some share of the profit; then doubles the number of employees the next month and offers each worker a share of the profit; then again doubles the workforce the following month and again gives out stock options. The salary is throughout kept constant at $\mathrm{c} / 2$. It is possible to show that by working out the stock option amounts in a way similar to the scheme described in my marketing model the job can be made attractive to each employee. This happens because the stock options are really a camouflaged Ponzi, just like my scheme described above. This paper would have served its purpose if it enables us to craft policies to prevent ordinary consumers and employees from being exploited.

The reason why giving shares to employees does not always lead to a crash is because productive activity can at times "catch up" with a Ponzi, and diffuse it $^{3}$. Even in my scheme, if as an entrepreneur you use the profit to start up new productive ventures and you strike lucky with one of those, it is possible for you to diffuse the Ponzi process. The same is true of the practice of wider and wider distribution of share options. These have the potential for a crash (and may even have contributed to the crash of 2007), but, since most firms are also trying to be productive, they can diffuse the expanding Camoponzi before it crashes.

The legality of Ponzis is not as open-and-shut a matter as is usually made out to be. Often those who run Ponzis, such as Bernard Madoff or the pioneer, Charles Ponzi (1882-1949), do not reveal to investors that it is a Ponzi. They put up a false front of productive investment taking place with the investors' money. That would be illegal, if for no other reason, because it involves deceit. But if someone runs a Ponzi or a Camoponzi, such as the one described above, by being fully transparent about what is being done with the money, it is not obvious that rational agents should not invest in it. The main reason for this is that there is no well-defined point at which a Ponzi collapses. All Ponzis and Camoponzis involve an ever-growing set of transactions, with customers making repeat purchases. Since, ultimately, the speed of this gets unmanageably rapid, we know that Ponzis will ultimately $\mathrm{crash}^{4}$. The trouble is that this, in itself, does not make it

\footnotetext{
${ }^{3}$ Furthermore, in infinite period models, it is possible, up to a point, to increase the income and consumption of the current generations without causing any decline in the consumption of future generations simply by each generation borrowing from the next (see Shell, 1971).

${ }^{4}$ For this reason my scheme would not work in a world with a finite termination date. The argument would unwind for the same reason as in Tirole (1982)—-see also Allen and Gorton (1993).
} 
irrational for the consumer to buy hotashes since there is no well-defined date when it crashes ${ }^{5}$. It can be common knowledge that it will eventually crash but it can still be rational for consumers to participate in it. We know this from related arguments in the literature about bubbles and crashes (see Abreu and Brunnermeier, 2003).

If consumers are willing to participate in a Ponzi with eyes wide open, it is not obvious that it should be banned. One can, instead, make the neoclassical argument that there should simply be full transparency. On the other hand, one can reasonably argue that individuals are unable to process the full complexity of Ponzis and also have self-control problems, and so they need to be protected from themselves; hence, Ponzis should be illegal.

The scheme I describe in this paper has the problem (or, in case you are the entrepreneur, the advantage) that it will not be easy to prove in practice that it is a Ponzi. Modern economics tells us that the value of a good is nothing but the value that consumers place on it. Contrary to what many economists of the mid-nineteenth century had thought, there is nothing intrinsic about value. If consumers value hotashes, hotashes have value. If they buy the package of hotash plus share, we know they value this bundle. There is no obvious way of knowing what the value of only the hotash is. This is what makes it difficult to prove that it is a Ponzi. Consumers have the right to pay what they wish for hotashes and that is what they are doing when they buy hotashes. This is the same reason why the widespread use of stock options to managers and consultants is not considered illegal. What this paper tried to show is that such practices are also disguised Ponzis and have probably contributed to the financial crash that occurred between 2007 and 2009. The march of modern economy thrives on unscrupulous entrepreneurs who stay one step ahead of the law. Stock options for consumers and others is one such idea.

The law will eventually catch up with it. But before that happens, this may be your chance to make money and get away to the Bahamas ${ }^{6}$.

\footnotetext{
${ }^{5}$ This is what makes the claim of the "impossibility of Ponzi survival" almost mystical. An analogy from the natural sciences is the claim that no object can travel at the speed of light. This is baffling because one can construct examples in theory where this is not true. Consider a fan with a single blade, which does one revolution per minute. The speed at which the far tip of the blade travels clearly depends on the length of the blade. By increasing the length we can make it go ever faster. So, for every real number, we can make the blade long enough so that the tip travels at a speed greater than that number. Though there is no point where this argument breaks down, we know that as the lengthening occurs, at some point, the blade tip will not function as the argument suggests.

${ }^{6}$ The relief is likely to be temporary, though, since, thanks to global warming, the Bahamas is likely to go underwater.
} 


\section{References}

Abreu, Dilip and Brunnermeier, Markus (2003), 'Bubbles and Crashes,' Econometrica, vol. 71, 173-204.

Akerlof, George and Shiller, Robert (2009), Animal Spirits: How Human Psychology Drives the Economy and Why it Matters for Global Capitalism, Princeton: Princeton University Press.

Allen, Franklin and Carletti, Elena (2008), 'The Role of Liquidity in Financial Crises,' in 2008 Jackson Hole Conference Proceedings, Federal Reserve Bank of Kansas City.

Allen, Franklin and Gorton, Gary (1993), 'Churning Bubbles,' Review of Economic Studies, vol. 60, 813-36.

Basu, Kaushik (2009), 'A Simple Theory of the Financial Crisis of 2007-09, with Implications for the Design of Stimulus Policy,' mimeo: Cornell.

Basu, Kaushik and Mitra, Tapan (2003), 'Aggregating Infinite Utility Streams with Intergenerational Equity,' Econometrica, vol. 71, 1557-63.

Basu, Kaushik and Mitra, Tapan (2007), 'Utilitarianism for Infinite Utility Streams: A New Welfare Criterion and Its Axiomatic Characterization,' Journal of Economic Theory, vol. 133, 350-73.

Brock, William (1970), 'An Axiomatic Basis for the Ramsey-Weiszacker Overtaking Criterion,' Econometrica, vol. 38, 927-9.

Maskin, Eric (1978), 'A Theorem on Utilitarianism,' Review of Economic Studies, vol. 45, 93-6.

Rubinstein, Ariel (1979), 'Equilibrium in Supergames with the Overtaking Criterion,' Journal of Economic Theory, vol. 21, 1-9.

Rubinstein, Ariel and Spiegler, Ran (2008), 'Money Pumps in the Market,' Journal of the European Economic Association, vol. 6, 237-53.

Shell, Karl (1971), 'Notes on the Economics of Infinity,' Journal of Political Economy, vol. 79, 1002-11.

Shell, Karl, Sidrauski, Miguel, and Stiglitz, Joseph (1969), 'Capital Gains, Income, and Savings,' Review of Economic Studies, vol. 36, 15-26.

Shiller, Robert (2000), Irrational Exuberance, Princeton: Princeton University Press.

Tirole, Jean (1982), 'On the Possibility of Speculation under Rational Expectations,' Econometrica, vol. 50, 1163-81. 